\title{
A Meme's-Eye View of Nonspeech Oral-Motor Exercises
}

\author{
Alan G. Kamhi, Ph.D. ${ }^{1}$
}

The publisher regrets a typographical error in the above article in Seminars in Speech and Language, Volume 29, Number 4, 2008, pages 331-338. On page 333, right column, line 15, the sentence reads "And does a nonspeech activity like sticking out the tongue become a speech-facilitating oral motor activity when it is used to help a child produce a / $\ni /$ ?"

The sentence should read "And does a nonspeech activity like sticking out the tongue become a speech-facilitating oral motor activity when it is used to help a child produce a $/ \theta /$ ?"

${ }^{1}$ University of North Carolina at Greensboro, Greensboro, North Carolina.

Address for correspondence and reprint requests: Alan G. Kamhi, Ph.D., University of North Carolina, Greensboro, NC (e-mail: agkamhi@uncg.edu).

Engagement in Clinical Practice; Guest Editors, Nina
Simmons-Mackie, Ph.D., BC-NCD, and Dana Kovarsky, Ph.D.

Semin Speech Lang 2009;30:57-57. Copyright (C) 2009 by Thieme Medical Publishers, Inc., 333 Seventh Avenue, New York, NY 10001, USA. Tel: +1(212) 584-4662. DOI 10.1055/s-0028-1121902. ISSN 0734-0478. 